\title{
Some Characteristic Properties of Ice Crystal Precipitation in the Summer Season at South Pole Station, Antarctica
}

\author{
By Noboru Sato and Katsuhiro Kikuchi \\ Department of Geophysics, Faculty of Science, Hokkaido University, Sapporo 060, Japan
}

Stephen C. Barnard and Austin W. Hogan

Atmospheric Sciences Research Center, State University of New York at Albany

Albany, New York 12222, U.S.A.

(Manuscript received 15 October 1980, in revised form 11 June 1981)

\begin{abstract}
Observations of ice crystals at Amundsen-Scott South Pole Station, Antarctica were made during January 1975 and November 1978. Results of analysis indicate that the maximum precipitation intensity varied between 0.01 and $0.2 \mathrm{~mm} \cdot \mathrm{hr}^{-1}$ and the size distribution of ice crystals could be expressed by the exponential equation, $N_{D}=N_{0}$ exp $(-\Lambda D)$, similar to other types of solid precipitation. The $Z-R$ relation, $Z=10 R^{1.0}$, was introduced for ice crystals. The relation between axial ratio $(c / a)$ and length of the $c$-axis for bullet and column types of ice crystals coincided with results previously reported.
\end{abstract}

\section{Introduction}

In recent years, there has been increasing interest in precipitation phenomena in the polar areas; including the water budget (Loewe, 1967), condition of snowfall and precipitation intensity. The method used to estimate precipitation amounts and the water budget is through a sequential measurement of snow poles (Bull, 1971). However, owing to the influence of drifting snow, which is occasionally accompanied by relatively strong winds, it is thought that the measured values do not provide an actual assessment of precipitation amounts grown by the sublimation and condensation processes in the free atmosphere. On the other hand, the amount of precipitation in these areas is expected to be correspondingly small. A true measure of the precipitation intensity in these areas has not previously been obtained.

One of the authors (K.K.) made observations of ice crystals at South Pole Station, Antarctica through the following periods of January (midsummer), 1975, and November (end of winter or beginning of austral summer), 1978. During the observation periods, the shapes of ice crystals were recorded by microphotographs (Kikuchi and Hogan, 1976, 1979) and replicated on glass slides by means of Formvar solution. The precipitation intensity, size distribution of ice crystals and the relation between the radar reflectivity factor and precipitation intensity were estimated using data from replicated ice crystals.

\section{Analytical method}

Observations using the replication method were made from 12 to 31 January 1975 and from 5 to 28 November 1978. During this period snow and ice crystal precipitation, with the exception of suspended "diamond dust" type crystals, was observed a total of eight days in the respective year. During precipitation, ice crystals were collected by natural sedimentation on $25 \times 75 \mathrm{~mm}$ glass slides coated with $0.5 \%$ Formvar solution and replicated. As expected from the air temperatures at the time of observation, the greater part of the ice crystals were bullets, combinations of bullets, columns, and crossed plates (formerly called side planes). In order to estimate the mass of ice crystals, the empirical formula $m=$ $1.3 a^{2} l$ for columnar and bullet types (Higuchi, 1956) was used, where $m$ is the mass in milligrams, $a$, the radius and $l$, the length of the column in millimeters. Nakaya and Terada's (1935) "powder snow" formula, $m=0.010 d^{2}$, where $d$ is the diameter of a circle just enclosing 
the crystal in millimeters, was used for the estimation of the mass of the ice crystals whose shapes were numerous combination of bullets, aggregates and uncertain types. The precipitation intensity was calculated from the exposure time, mass, and the measuring area of the printing paper.

The size distribution of the ice crystals was estimated using the same prints. The melted diameters of ice crystals smaller than $0.05 \mathrm{~mm}$ were not measured in this examination. The number of ice crystals larger than $0.05 \mathrm{~mm}$ were counted for every $0.1 \mathrm{~mm}$. From these measurements, a horizontal plane size distribution, $N_{H}$ (number of particles falling upon a horizontal surface per second per $\mathrm{m}^{2}$ per diameter interval $0.1 \mathrm{~mm}$ ) was obtained. This horizontal plane size distribution was converted to a spatial size distribution using an empirical relationship between fall velocity and the melted diameters of columnar ice crystals (Kajikawa, 1973, 1976).

The size distribution of precipitation particles, in general, is well represented by the following exponential distribution (Marshall and Palmer, $1948), N_{D}=N_{0} \exp (-\Lambda D)$, where $D$ is the melted diameter, $N_{D} d D$ is the number of ice crystals having a melted diameter between $D$ and $D+d D$, in a unit volume of space, and $N_{0}$ is the value of $N_{D}$ for $D=0$. The measurement technique used by Sekhon and Srivastava (1970) was adopted to represent $N_{0}\left(\mathrm{~m}^{-3} \cdot \mathrm{mm}^{-1}\right), \Lambda\left(\mathrm{mm}^{-1}\right)$ and $D_{0}(\mathrm{~mm})$ as a function of precipitation intensity $R\left(\mathrm{~mm} \cdot \mathrm{hr}^{-1}\right) . \quad D_{0}$ means the median volume diameter. The precipitation content $M\left(\mathrm{mg} \cdot \mathrm{m}^{-3}\right)$, which is the mass of ice crystals per unit volume of space, was also calculated as a function of $R$. Size distributions were calculated using 41 collections from January 1975 and 31 from November 1978. From these the relation between the radar reflectivity factor $Z\left(\mathrm{~mm}^{6} \cdot \mathrm{m}^{-3}\right)$ and precipitation intensity $R(\mathrm{~mm}$. $\mathrm{hr}^{-1}$ ) was determined empirically as $Z=B R^{\beta}$.

\section{Results}

\subsection{Precipitation intensity}

When ice crystals were replicated during the observation period, the surface air temperature varied from $-23^{\circ} \mathrm{C}$ to $-35^{\circ} \mathrm{C}$ in January 1975 and from $-333^{\circ} \mathrm{C}$ to $-45^{\circ} \mathrm{C}$ in November 1978 . The surface temperature inversion in November 1978 was stronger than that in January 1975.

Sky cover was reported in tenths of total cloud cover. When ice crystals were falling, the sky condition was one of three broad categories.

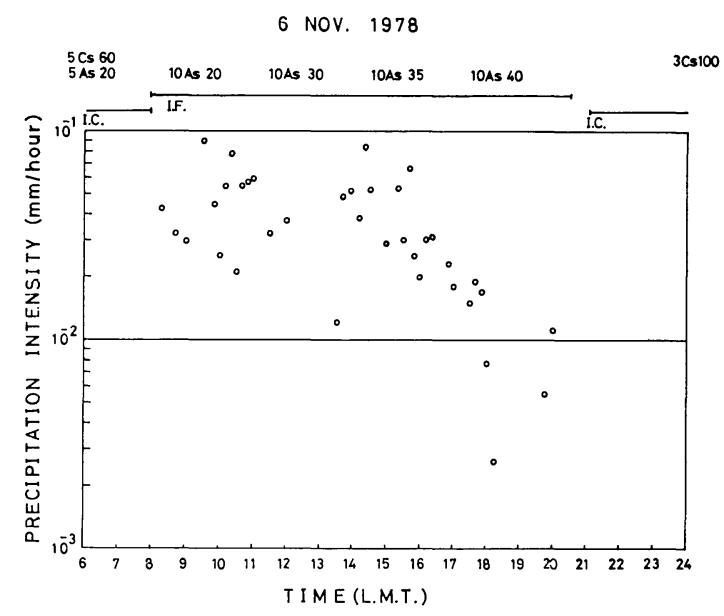

Fig. 1 Precipitation intensity of ice crystals (I.C.) and ice fog (I.F.) on November 6, 1978.

The first type consisted of skies nearly overcast by cirrus type clouds. The second, occurred when the sky was mostly overcast with altostratus or altocumulus clouds. The last, when two or three tenths of altostratus were seen as the lowest layer of cloud and more than five tenths of the cirrus type cloud as the second layer.

Fig. 1 is a time variation of ice crystal (I.C.) precipitation intensity and ice fog (I.F.) on November 6, 1978. In this case, ice particles were precipitating from altostratus clouds. The precipitation intensity ranged between $1 \times 10^{-1}$ and $1 \times 10^{-2} \mathrm{~mm} \cdot \mathrm{hr}^{-1}$. When the height of cloud base rose above $3,500 \mathrm{ft}$ a.s.1. (above surface level), the intensity suddenly decreased to approximately $10^{-3} \mathrm{~mm} \cdot \mathrm{hr}^{-1}$ and precipitation changed from ice fog to ice crystals. The maximum precipitation intensity was defined as that in which the intensity showed the maximum value during a continuous precipitation. In this case, the maximum precipitation intensity was $8.9 \times$ $10^{-2} \mathrm{~mm} \cdot \mathrm{hr}^{-1}$ at $0930 \mathrm{LMT}$ (180th maridian time).

Hogan (1975) emphasized the existence of cirrus cloud bands at higher altitudes during precipitation periods. It was hypothesized that small ice crystals, from these cirrus clouds, settled into the saturated layers, serving to nucleate columnar ice crystals which then precipitated to the surface. Fig. 2 shows the relation between the maximum precipitation intensity and sky conditions; namely, cirrostratus clouds, altostratus plus cirrostratus or cirrus and altostratus or altocumulus clouds. Although it 


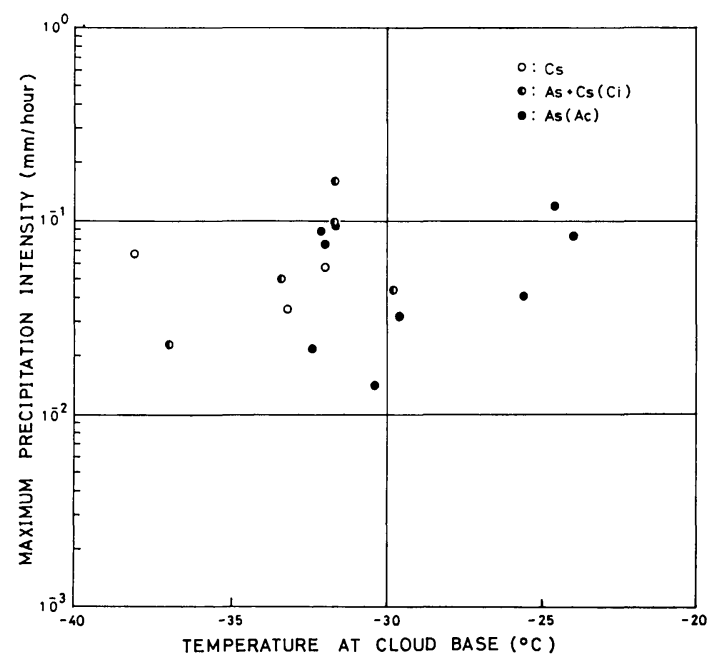

Fig. 2 A relation between the maximum precipitation intensity and sky conditions.

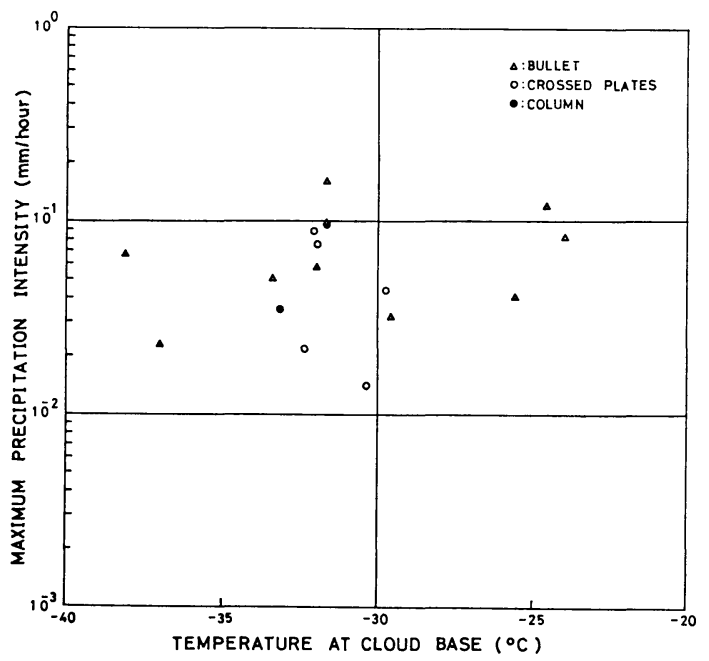

Fig. 3 A relation between the maximum precipitation intensity and the shape of ice crystals.

seems that the two layer cloud type system shows a relatively large maximum precipitation intensity compared with the single cloud type system as seen in the figure, there was no distinct tendency. As the shapes of ice crystals are determined by air temperature and supersaturation with respect to ice, the relation between the maximum precipitation intensity and the shapes of ice crystals observed is shown in Fig. 3. As seen in the figure, there was no relation between them, although it was recognized that the most typical shapes of ice crystals at South Pole Station during January (austral midsummer) and No-

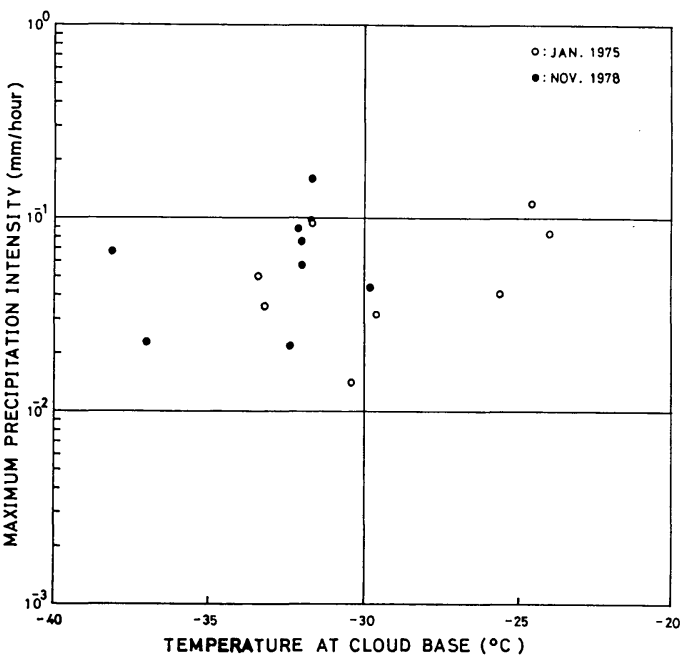

Fig. 4 The maximum precipitation intensity in all precipitation events observed in January 1975 and November 1978.

vember (end of winter or beginning of austral summer) were bullets and combinations of bullets.

The maximum precipitation intensity in all precipitation events is shown in Fig. 4. The vertical axis is the maximum precipitation intensity and the horizontal axis the air temperature at the cloud base, determined from the sounding data. The results of January 1975 (open circles) and November 1978 (solid circles) are plotted. The maximum precipitation intensity for two seasons was in a range from approximately 0.01 to $0.2 \mathrm{~mm} \cdot \mathrm{hr}^{-1}$. The largest value of the maximum precipitation intensity, $0.16 \mathrm{~mm}$. $\mathrm{hr}^{-1}$, was obtained on November 10, 1978, although it should be noted that precipitation intensities of this magnitude occur only for brief periods.

\subsection{Size distribution of ice crystals}

Fig. 5 is a plot of $\rho_{w} N_{D} D_{0}^{4} / M$ vs. $D / D_{0}$ on semi-logarithmic scales adopted from Sekhon and Srivastava (1970), where $\rho_{w}$ is the density of water. It is seen that the circles on the figure may be represented by a straight line. The equations of lines of least square best fit are as follows:

$$
\begin{gathered}
\rho_{w} N_{D} D_{0}{ }^{4} / M=36 \exp \left(-3.3 D / D_{0}\right) \\
\quad(\text { January 1975) } \\
\rho_{w} N_{D} D_{0}{ }^{4} / M=53 \exp \left(-3.5 D / D_{0}\right)
\end{gathered}
$$

(November 1978)

The mean values of $D_{m} / D_{0}$, where $D_{m}$ is the 

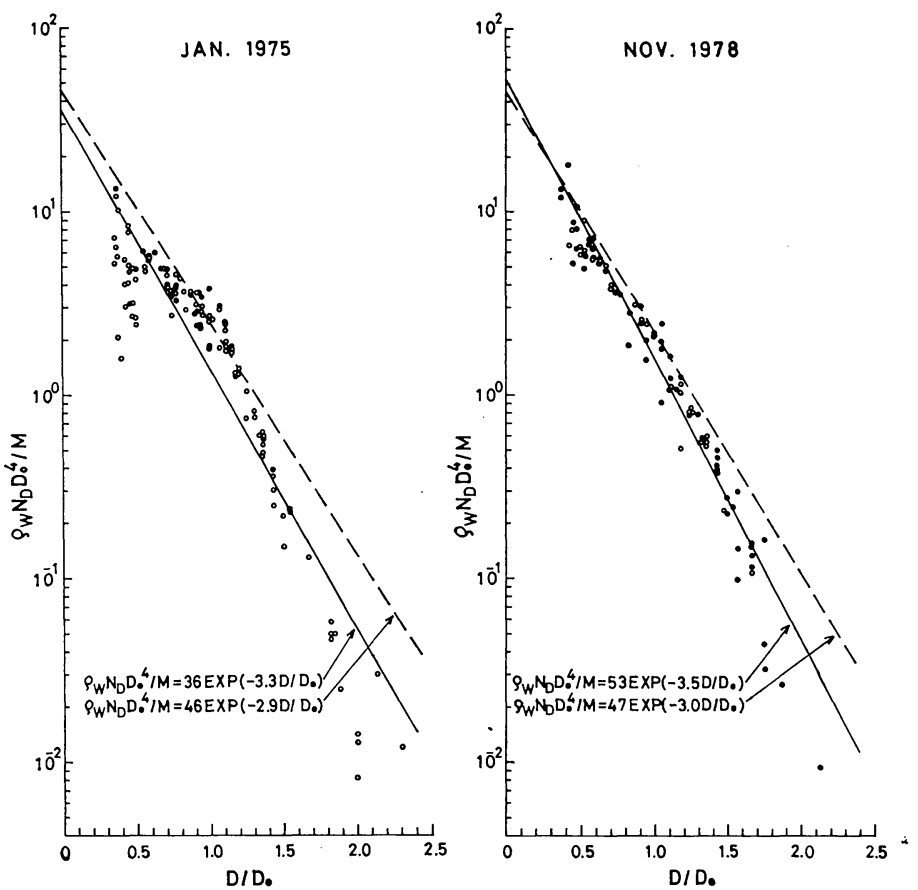

Fig. 5 Size distributions of ice crystals observed in January 1975 and November 1978.

maximum melted diameter, were 1.47 (January 1975) and 1.51 (November 1978). Using these values, the theoretical lines of $\rho_{w} N_{D} D_{0}^{4} / M$ vs. $D / D_{0}$ become:

$$
\begin{gathered}
\rho_{w} N_{D} D_{0}{ }^{4} / M=46 \exp \left(-2.9 D / D_{0}\right) \\
\quad(\text { January 1975) } \\
\rho_{w} N_{D} D_{0}^{4} / M=47 \exp \left(-3.0 D / D_{0}\right)
\end{gathered}
$$

(November 1978)

The theoretical lines which are also shown in Fig. 5, drawn as a dashed straight line are similar to the solid straight lines roughly. Therefore, it is concluded that the exponential equation, $N_{D}=N_{0} \exp (-\Lambda D)$, expresses the size distribution for ice crystal precipitation adequately.

The calculated values of $N_{0}, A, M$ and $D_{0}$, as a function of precipitation intensity $R$, for these ice crystal events and other precipitation types are summarized in Table 1 . The ranges of precipitation intensity used to calculate the size distribution were $0.0036 \sim 0.12 \mathrm{~mm} \cdot \mathrm{hr}^{-1}$ in January 1975 and $0.0053 \sim 0.16 \mathrm{~mm} \cdot \mathrm{hr}^{-1}$ in November 1978. It is seen from Table 1 that the results of analysis for both seasons coincide well. From these results, it is understood that the slope of the straight line expressed by the exponential equation hardly changes, even though the precipitation intensity changes. The value of $N_{0}$, expressed as a function of $R$, was previously reported to have a numerical in the order of $10^{3}$ to $10^{4}$ for precipitation. The data obtained for both seasons at South Pole for ice crystals are larger than previous values by $10^{2}$ to $10^{3}$.

\section{$3.3 Z-R$ relation of ice crystals}

The calculated value of the $Z-R$ relation for ice crystals is shown in Fig. 6. The vertical and horizontal axes are the radar reflectivity factor $Z\left(\mathrm{~mm}^{6} \cdot \mathrm{m}^{-3}\right)$ and precipitation intensity $R(\mathrm{~mm}$. $\left.\mathrm{hr}^{-1}\right)$, respectively. The open circles indicate the data of January 1975 and the solid circles those of November 1978 . The $Z-R$ relation generally is presented as $Z=B R^{\beta}$. The result of this analysis was $B=12, \beta=1.1$ during January 1975 and $B=12, \beta=1.0$ for November 1978 , as shown in Table 1. Hence, the empirical formula for the data of two summer seasons at South Pole Station, was found to be: $Z=12 R^{1.1}$. As seen in Table 1 , the value of ice crystal precipitation is smaller by one or two orders of magnitude than those of other precipitation types. This is probably due to the fact that the maximum value of the melted diameter is smaller than that of other precipitation types. The maximum value of the melted diameter was found to be $0.37 \mathrm{~mm}$ 


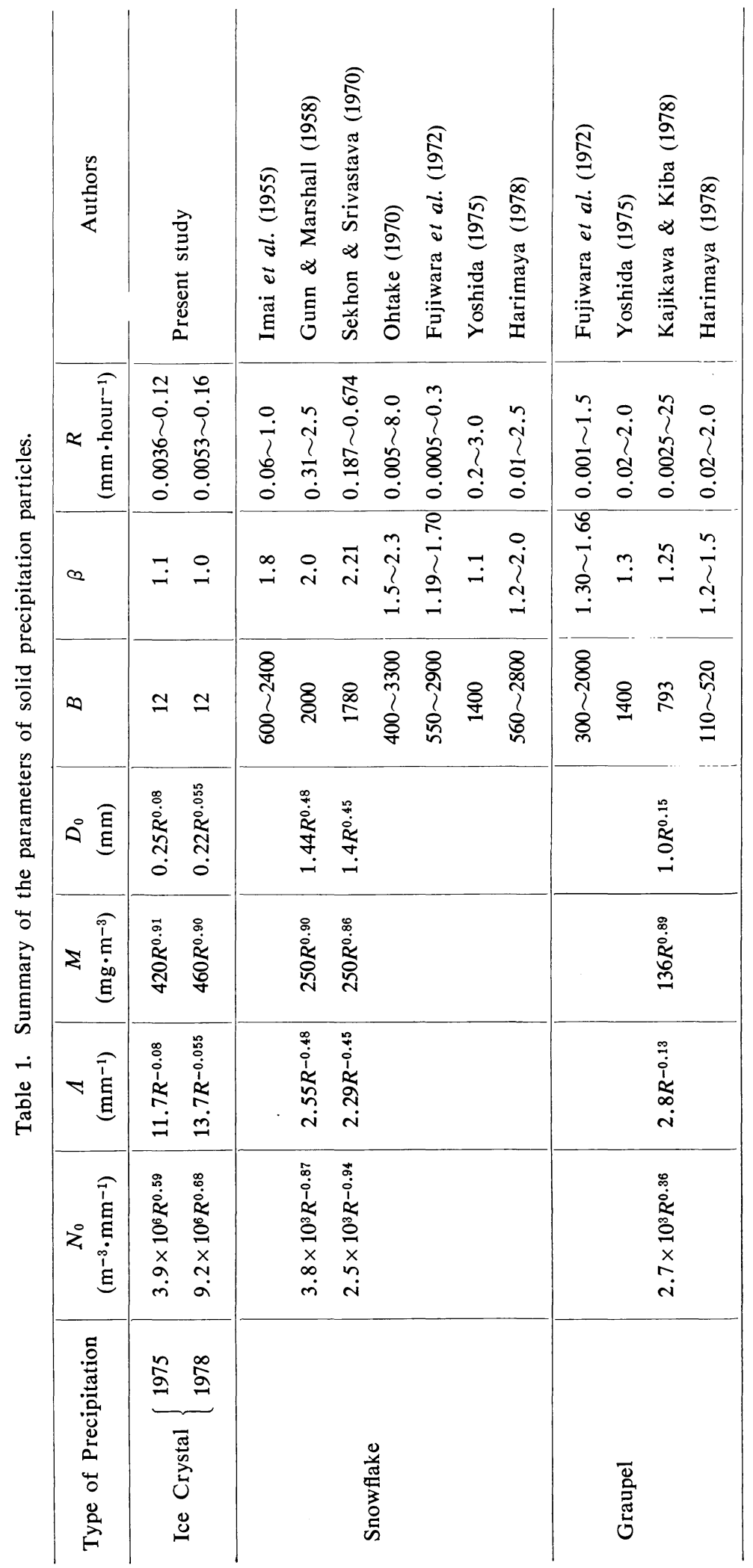




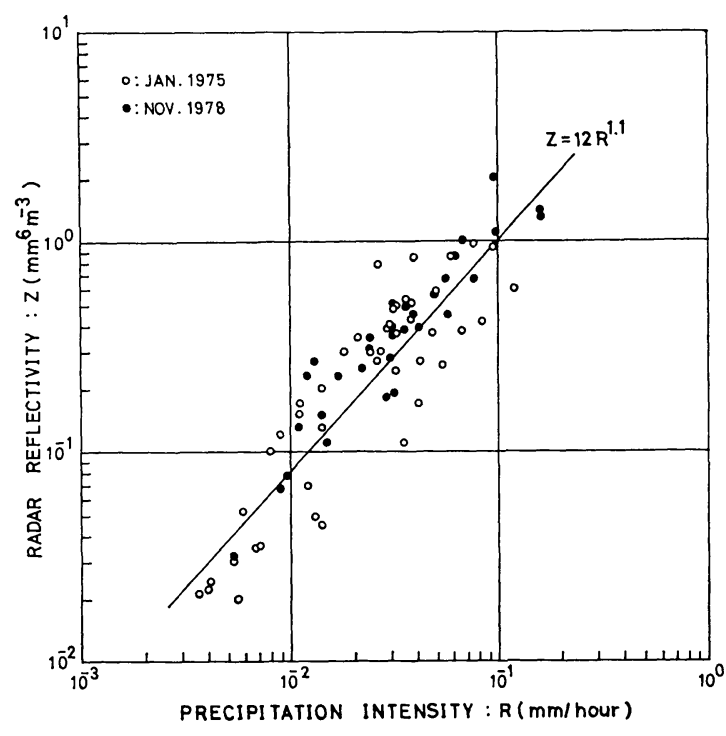

Fig. 6 A relation between the radar reflectivity factor $Z\left(\mathrm{~mm}^{6} \cdot \mathrm{m}^{-3}\right)$ and precipitation intensity $R\left(\mathrm{~mm}^{\circ}\right.$ hour $\left.^{-1}\right)$.

in January 1975 and $0.40 \mathrm{~mm}$ in November 1978 . The value of $\beta$ indicates the smallest value in the measurement series which has been obtained to data. This is due to the fact that the changes in the range of melted diameter $D$ with precipitation intensity $R$, were small. It is thought that the $Z-R$ relation for ice crystals, except for the diamond dust type ice crystals, during the summer season at South Pole may be expressed sufficiently by $Z=10 R^{1.0}$. In the case of diamond dust type ice crystals observed by Kikuchi and Hogan (1979), $Z$ and $R$ were between $10^{-4}$ and $10^{-5}$ $\mathrm{mm}^{6} \cdot \mathrm{m}^{-3}$ and $10^{-4}$ and $10^{-5} \mathrm{~mm} \cdot \mathrm{hr}^{-1}$, respectively.

\subsection{Growth mode of column type ice crystals}

The relation between the $a$-and $c$-axes of column type ice crystals used to estimate precipitation intensity in January 1975 is shown by the large open circles in Fig. 7. In this figure, the broken lines indicate the warm and cold column region drawn by Ono (1969) and the solid line is the empirical relationship for the column type crystals at the ELK Mountain observed by Auer and Veal (1970). When a comparison is made between the measurements of column type ice crystals obtained by Auer and Veal with that of this study, the latter show a tendency to be somewhat longer in the $c$-axis, than the former. Other observations of column type ice crystals, Kikuchi (1968) and Kikuchi and Yanai (1971), are plotted by solid, cross and double circles,

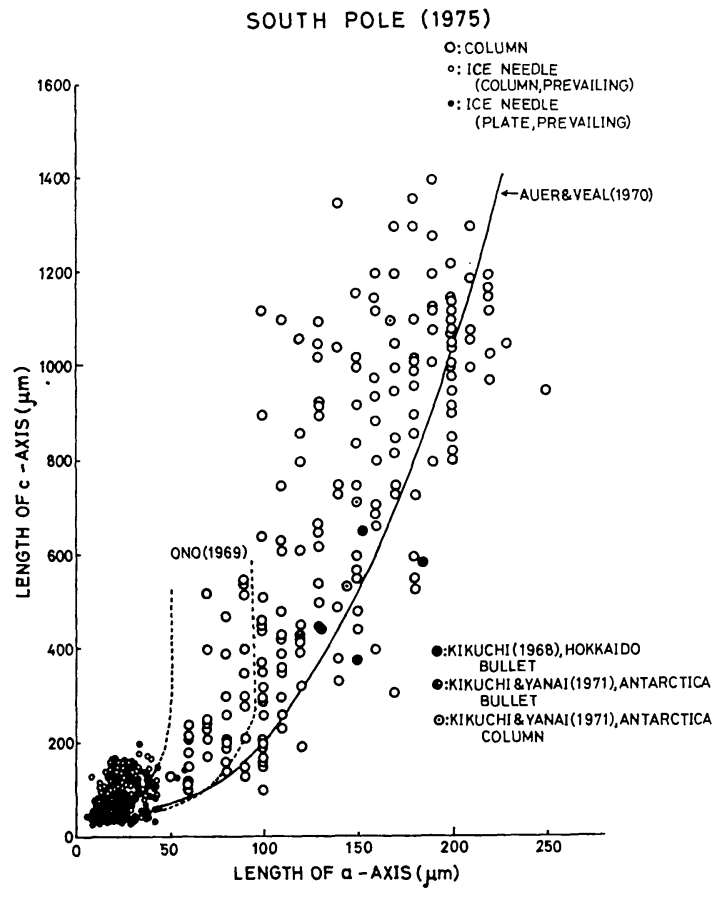

Fig. 7 A relation between $a$ - and $c$-axes of column type ice crystals.

respectively. The data of the present study are nearly coincident with these values. The data for relatively small or diamond dust type columnar ice crystals, are plotted in the same figure (Kikuchi and Hogan, 1979). The small open circles indicate the columnar diamond dust type ice crystals measured when column type ice crystals prevailed. The small solid circles show the same type crystals measured when the plate type ice crystals prevailed. The data for column type ice crystals in this study are connected with that of columnar diamond dust type ice crystals. It is therefore concluded that the region of growth of column type ice crystals, as introduced by Ono (1969), should be extended to shorter and longer regions of the $a$-axis.

Fig. 8 shows the relation between axial ratio $(c / a)$ and length of $c$-axis of column type tce crystals during a precipitation event on January 27,1975 , when column type ice crystals predominated. In this figure, the solid circles show the results of the present study and open triangles, circles, and squares, show the mean values observed at the locations of St. $771\left(82^{\circ} 48^{\prime} \mathrm{S}\right.$, $40^{\circ} 32^{\prime} \mathrm{E}, \quad 3,370 \mathrm{~m}$ a.s.1.), St. $903 \quad\left(80^{\circ} 20^{\prime} \mathrm{S}\right.$, $39^{\circ} 52^{\prime} \mathrm{E}, 2,933 \mathrm{~m}$ a.s.1.) and South Pole $(2,804 \mathrm{~m}$ a.s.1.) by Kikuchi and Yanai (1971). A solid line indicates the same data th Fig. 7 by Auer and 


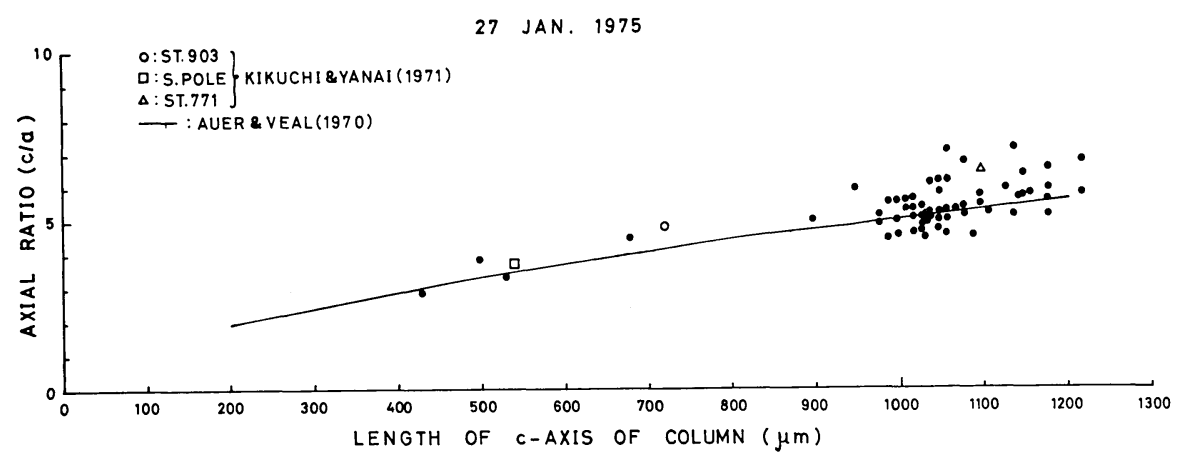

Fig. 8 A relation between the axial ratio $(c / a)$ and length of $c$-axis of column type ice crystals.

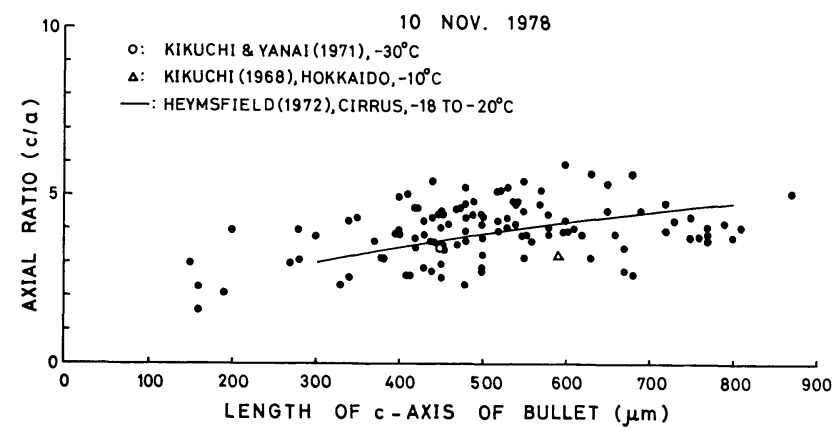

Fig. 9 A relation between the axial ratio $(c / a)$ and length of $c$-axis of bullet type ice crystals.

Veal (1970). These results coincided with each other. Fig. 9 shows the relation between axial ratio $(c / a)$ and length of $c$-axis for bullet type ice crystals which precipitated predominantly on November 10, 1978. In this figure, solid circles show the results of the present study and an open circle shows the mean value observed under $-30^{\circ} \mathrm{C}$ conditions at the South Pole (Kikuchi and Yanai, 1971). The open triangle is the mean value of results observed at the Mt. Teine Cloud Physics Observatory, Hokkaido under $-10^{\circ} \mathrm{C}$ conditions (Kikuchi, 1968). The solid line is the result observed by Heymsfield (1972) under -18 to $-20^{\circ} \mathrm{C}$ conditions in cirrus clouds. They seem to coincide with each other although the relatively small value of the axial ratio of the Mt. Teine crystals may be due to warmer temperatures. The relation between axial ratio $(c / a)$ and length of the $c$-axis of column type ice crystals to cloud forms was considered. Fig. 10 shows the results of precipitation from altostratus, cirrostratus, and cirrostratus plus altostratus clouds. Cloud heights were $3,000,12,000$, and 3,000 and 8,000 feet a.s.1., respectively. As seen in the figure, the length of $c$-axis of columnar ice crystals precipi- tating from altostratus cloud alone was shorter than other cloud forms, while the length of $c$ axis of columns precipitating from two layers of clouds was longer than others. This is an agreement with the findings of Kikuchi and Yanai (1971). The maximum length of the $c$-axis of columnar type precipitation in this study was approximately $1.6 \mathrm{~mm}$.

\section{Conclusions}

Some characteristic properties of ice crystal precipitation in the summer season at South Pole Station, Antarctica were considered. The maximum precipitation intensity over two summer seasons was fairly consistent, varying from 0.01 to $0.2 \mathrm{~mm} \cdot \mathrm{hr}^{-1}$. Therefore, it is concluded that these values are representative of the summer season at the South Pole area.

Hogan (1975) suggested that summer season precipitation was practically unrecordable, and while reported as a "trace" it sometimes achieved a depth of $3 \mathrm{~mm}$ in a few hours during calm periods. This converts to an equivalent water hourly precipitation of about $0.1 \mathrm{~mm}$. The time variation of precipitation intensity at South Pole 


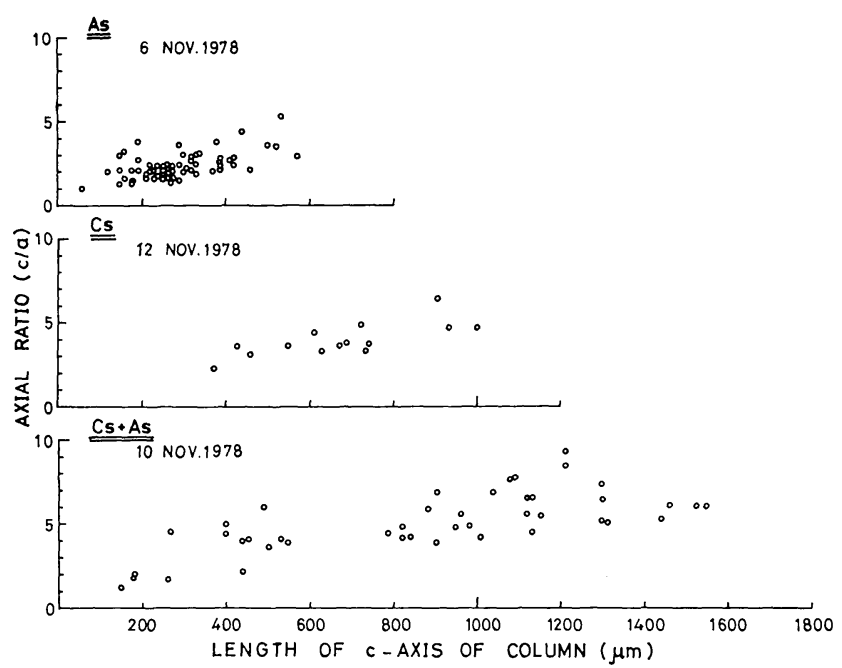

Fig. 10 A relation between the axial ratio $(c / a)$ and length of $c$-axis of column type ice crystals precipitating from different cloud forms.

Station is not large owing to the presence of stratus clouds $\left(C_{s}, A_{s}\right)$ during nearly every ice crystal precipitation event. The average precipitation intensity found during this study was approximately $0.1 \mathrm{~mm} \cdot \mathrm{hr}^{-1}$, which is in good agreement with those obtained by Hogan.

The size distribution of ice crystals observed at the South Pole was expressed by the exponential equation, $N_{D}=N_{0} \exp (-A D)$, in the same manner as other types of precipitation. The $Z-R$ relation, $Z=10 R^{1.0}$ was introduced for ice crystals. From the analysis of $a$ - and $c$-axes, it was concluded that the region of growth of column type ice crystals introduced by Ono (1969) should be extended to both shorter and longer regions of the $a$-axis. The relation between axial ratio $(c / a)$ and length of the $c$-axis for bullet and column types of ice crystals coincided with the results previously reported.

\section{Acknowledgements}

A part of this research was supported by National Science Foundation Grants Opp 7422534 and DPP7623110 and K. Kikuchi's travel from Japan to the United States was supported by the General Electric Foundation.

\section{References}

Auer, A. H. and D. L. Veal ,1970: The dimension of ice crystals in natural clouds. J. Atmos. Sci., 27, 919-926.

Bull, C., 1971: Snow accumulation in Antarctica. Research in the Antarctic. Ed. by L. O. Quam,
367-421.

Fujiwara, M., T. Yanase and K. Takahashi, 1972: Relationships between radar reflectivity $Z$ and the rainfall intensity $R$ on snowflake and graupel (in Japanese). Tenki, 19, 31-36.

Gunn, K. L. S. and J.S. Marshall, 1958: The distribution with size of aggregate snowflakes. $J$. Meteor., 15, 452-461.

Harimaya, T., 1978: Observation of size distribution of graupel and snowflake. J. Fac. Sci., Hokkaido Univ., Ser. VII, 5, 67-77.

Heymsfield, A., 1972: Ice crystal terminal velocities. J. Atmos. Sci., 29, 1348-1357.

Higuchi, K., 1956: A new method for the simultaneous observation of a large number of falling snow particles. J. Meteor., 13, 274-278.

Hogan, A. W., 1975: Summer ice crystal precipitation at the South Pole. J. Appl. Meteor., 14, 246-249.

Imai, I., M. Fujiwara, I. Ichimura and Y. Toyama, 1955: Radar reflectivity of falling snow. Pap. Meteor. Geophys., 6, 130-139.

Kajikawa, M., 1973: Laboratory measurement of falling velocity of individual ice crystals. $J$. Meteor. Soc. Japan, 51, 263-272.

- 1976: Observation of falling motion of columnar snow crystals. J. Meteor. Soc. Japan, 54, 276-284.

distribution of graupel particles (in Japanese). Tenki, 25, 390-398.

Kikuchi, K. 1968: On snow crystals of bullet type. J. Meteor. Soc. Japan, 46, 128-132.

- and A.W. Hogan, 1976: Snow crystal observations in summer season at AmundsenScott South Pole Station, Antarctica. J. Fac. Sci., 
Hokkaido Univ., Ser. VII, 5, 1-20. , and 1979: Properties of diamond dust type ice crystals observed in summer season at Amundsen-Scott South Pole Station. J. Meteor. Soc. Japan, 57, 180-190.

, and K. Yanai, 1971: Observation on the shapes of snow crystals in the south pole region in the summer. Antarctic Record, 41, 34-41.

Loewe, F., 1967: The water budget in Antarctica. Proc. Symposium on Pacific-Antarctic Science. National Science Museum, Tokyo, 101-110.

Marshall, J.S. and W. M. Palmer, 1948: The distribution of raindrops with size. J. Meteor., 5, 165-166.

Nakaya, U. and T. Terada, Jr., 1935: Simultaneous observations of the mass, falling velocity and form of individual snow crystals. J. Fac. Sci., Hokkaido Univ., Ser.1I, 1, 191-200.

Ohtake, T., 1970: Radar reflectivity of aggregated snowflakes. Reprint. 14th Radar Meteor. Conf., 1970, Tucson, 209-210.

Ono, A., 1969: The shape and riming properties of ice crystals in natural clouds. J. Atmos. Sci., 26, 138-147.

Sekhon, R. S. and R. C. Srivastava, 1970: Snow size spectra and radar reflectivity. J. Atmos. Sci., 27, 299-307.

Yoshida, T., 1975: The relation between radar reflectivity and snowfall intensity by kerosen-soaked filter paper method (in Japanese with English abstract). J. Meteor. Res., 27, 107-111.

\title{
夏季の南極点基地における水晶の性質
}

\author{
佐藤昇・㐘 地勝 弘 \\ 北海道大学理学部地球物理学教室 \\ Stephen C. Barnard and Austin W. Hogan \\ ニューヨーク州立大学大気科学研究センター
}

1975 年 1 月と 1978 年 11 月の二度にわたって, 南極点基地で氷晶の観測を行なった。解析の結果, 最大降水強 度は $0.01 \sim 0.2 \mathrm{~mm} \cdot \mathrm{hr}^{-1}$ の範囲で，粒度分布は他の降水と同じく， $N_{D}=N_{0} \exp (-\Lambda D)$ の形で表わされること がわかった。また，レーダー反射強度因子 $(Z)$ と降水強度 $(R)$ の間には， $Z=10 R^{1.0}$ の関係があった。その他， 砲弾集合や角柱結晶の軸比 $(c / a)$ と結晶主軸の長さの関係は, 従来報告されている結果にほぼ等しかった。 